\title{
O ENSINO DE LITERATURA NO BRASIL: UMA ABORDAGEM NO CURRÍCULO DO ENSINO MÉDIO
}

\author{
Literature teaching in Brazil: an approach to the high school curriculum
}

\author{
Juliana Cristina Ferreira \\ https://orcid.org/0000-0002-3416-7314 \\ Universidade Federal de Uberlândia, Programa de Pós-Graduação em Estudos \\ Literários, Uberlândia, MG, Brasil. 38408-100 - secpplet@ileel.ufu.br
}

\begin{abstract}
Resumo: Este texto discute alguns aspectos abordados no Ensino de Literatura no Brasil e aponta algumas maneiras de como a literatura deve ser trabalhada em sala de aula, para que haja a compreensão do aluno-leitor. Nesse sentido, coloca-se em pauta aspectos históricos, sociais e culturais que estão presentes nos textos literários e que são pleiteados pelo professor-mediador para o entendimento e gosto pela leitura deleite, por parte do aluno. Assim, fundamenta-se em aportes teóricos propostos por Candido (2006) que apresenta modos e conceitos sobre o estilo como o texto literário é compreendido, através do olhar investigativo do aluno. Nesse sentido, elucida acerca da contextualização e estilização do texto, por meio da mediação do(a) professor(a). Conta-se também com a contribuição da autora Malard (1985) que revela algumas razões para a aprendizagem da literatura através da leitura crítica sobre os textos. Assim, a metodologia utilizada nesse texto baseia-se na pesquisa bibliográfica. Quanto aos resultados desse estudo, conclui-se que a melhor maneira de trabalhar os textos literários para o entendimento e gosto pela leitura do aluno faz-se pela individualização do ledor, em sala de aula, com análise, crítica, adequação, intervenção e contextualização expressa pelo professor mediador.
\end{abstract}

Palavras-chave: Ensino de Literatura. Metodologia. Contextualização.

Abstract: This text discusses some aspects addressed in Literature Teaching in Brazil and points out some ways of how literature should be worked in the classroom, so that there is the understanding of the student-reader. In this sense, it is placed on the historical, social and cultural aspects that are present in the literary texts and that are requested by the teacher-mediator for understanding and taste for reading satisfactory, on the part of the student. Thus, it is based on theoretical contributions proposed by Candido (2006) who presents modes and concepts about the style as the literary text is understood, through the student's investigative view. In this sense, it elucidates about the contextualization and stylization of the text, through the mediation of the teacher. The contribution of the author Malard (1985) reveals some reasons for learning Literature through critical reading on the texts. The methodology used in this text is based on bibliographical research. As for the result this study, it is concluded that the best way to work the literary texts for the understanding and taste for the student's reading is by the individualization of the reader, in the classroom, with analysis, criticism, adequacy, intervention and contextualization expressed by the mediator teacher.

Keywords: Teaching Literature. Methodology. Contextualization.

Seja em nome da ordem, da liberdade ou do prazer, o certo é que a 
Literatura não está sendo ensinada para garantir a função essencial de construir e reconstruir a palavra que nos humaniza. Em primeiro lugar porque falta um objeto próprio de ensino. Os que se prendem aos programas curriculares escritos a partir da história da literatura precisam vencer uma noção conteudística do ensino para compreender que, mais que um conhecimento literário, o que se pode trazer ao aluno é uma experiência de leitura a ser compartilhada.

(COSSON, 2006, p. 23).

\section{Uma breve discussão sobre o Ensino de Literatura}

A literatura é uma arte que se manifesta por meio da escrita, da comunicação, da linguagem e da criatividade do ser humano. É considerada uma fonte que transmite conhecimentos: culturais, artísticos, religiosos e modos de vida, por meio dos textos fictícios. Por essa razão, os textos literários despertam no leitor emoções e contribuem para a (re)criação do pensamento humano. Assim, entende-se que a estética é sensível porque a literatura auxilia no desenvolvimento educacional e imaginativo, além de ampliar os conhecimentos linguístico e cognitivo.

Nesse sentido, Candido (1995) afirma que a literatura desperta no leitor sensibilidade, a fim de atribuir ao sujeito aspectos situacionais e pertinentes à compreensão, à crítica e à reflexão sobre os acontecimentos ocorridos na sociedade, à medida que esta possibilita novos olhares diante da condição humana. Desse modo, a leitura e a compreensão literária permitem ao sujeito-leitor pensar sobre o mundo em seu entorno e ampliar seus conhecimentos.

Ao subjazer dessa visão cultural e estética da literatura, pressupõe-se, neste artigo, que o contato com texto literário contribui no sentido de que o leitor seja transportado para a tessitura do texto, a fim de embarcar na leitura, fazendo assim, uma viagem ao mundo ficcional no qual poderá conhecer inúmeros lugares, acontecimentos históricos, sociais e culturais de diversas nações.

Nesse sentido, Eco (2000) ressalta que durante a leitura de um texto literário o leitor é transportado pela viagem da imaginação porque o texto conduz a caminhar pelos espaços e bosques através da descrição das cenas que, consequentemente, fazem com que o leitor possa sentir-se um personagem de um daqueles lugares inimagináveis. A leitura literária motiva, dessa forma, a fruição dos pensamentos acerca desses possíveis fatos inimagináveis.

Ao ter em vista essa riqueza dos textos literários, por transmitirem conhecimentos e favorecerem o imaginário do leitor, Almeida (2014) esclarece que a literatura está presente na vida social do ser humano desde a antiguidade grega; época em que os poemas épicos de Homero eram declamados em público, e a dramaturgia de Aristófanes, Plutarco e outros, tomavam conta dos teatros na Grécia a fim de mostrar à plateia a arte, os modos de vida política e os costumes daquele povo, por meio da escrita. Cardoso (2002) argumenta que os poemas, as tragédias e as comédias gregas marcaram a história da literatura barroca e renascentista no ocidente, por serem inspiradas em verossímeis fatos históricos da 
humanidade.

Assim, compreendida como uma maneira de transmitir conhecimentos, a literatura no Brasil está presente desde os tempos coloniais, no século XVI, período em que os jesuítas utilizavam textos literários para representarem o respeito pelas Belas Letras, por conseguinte, como maneira artística de revelar a realidade, a cultura e os modos de vida de Portugal aos indígenas realidade esta distanciada do que os aborígenes viviam no Brasil.

Seguindo este caminho, essa forma de ensino que distancia a literatura da realidade do aluno persevera ao longo do tempo como observa Malard (1985), apesar de o ensino de literatura ter sido incluído no currículo escolar com a Reforma Educacional de 1889, a leitura crítica dos textos literários continua distante e ausente do contexto social do aluno, pois visa, de maneira historicista, o conhecimento da biografia, estilo de escrita e Escola Literária a que pertence o autor.

Ao falar em ensino historicista da literatura, Souza (1999) observa que os estudos literários no Brasil, no século XIX, eram constituídos por duas vertentes de ensino: uma retórica-poética e outra historicista. Todavia, entre essas vertentes, com a modernização da sociedade, a segunda começou a ganhar mais espaço no ensino, por se tratar de uma aprendizagem mais conteudista e favorecer um estudo periódico, que enfatiza a caracterização de autores, épocas e Escolas Literárias.

Desse modo, ao debruçar sobre a vertente historicista do ensino de literatura no Brasil, no século XIX, percebe-se que essa forma de transmitir o conhecimento literário configurouse na atualidade. Assim, sonega-se o vigor desse ensino nos currículos escolares do Ensino Médio, uma vez que, as aulas de literatura, além de serem divididas com a disciplina de Língua Portuguesa se reduzem à leitura de fragmentos de alguma obra que aparece no livro didático, sem uma abrangência conceitual acerca do que se trata tal texto literário (MALARD, 1985). Por um lado, esse recorte inserido no livro didático não esgota nem torna os fatos exaustivos, mas por outro lado, pode retirar do alunado o sentido, o elo entre o texto ficcional e a realidade, uma vez que o texto literário não é apresentado na íntegra ao aluno-leitor.

\section{A literatura no Ensino Médio}

A literatura, por ser rica em saberes e em culturas, está presente como disciplina no ensino brasileiro desde o período colonial, no século XVI, quando os textos literários eram utilizados pelos padres jesuítas, como uma ferramenta no ensino. Esses mestres recorriam aos textos literários para representar as Belas Artes e a realidade distante: a de Portugal (MALARD, 1985). Assim, os teatros e poesias jesuíticas tinham objetivos religiosos e catequéticos, com a finalidade de doutrinar o indígena, como mostra o trecho do poema à Virgem Maria, de Anchieta (1988):

Cantar? Calar? Ó mãe de Jesus toda santa, cala-se minha boca ou teus louvores canta? $\mathrm{O}$ teu piedoso amor, com que a mente aguilhoas, 
manda cantar, senhora, estas modestas loas.

Mas teme em língua impura exaltar-te as grandezas,

pois que manchada já de muitas vis torpezas.

(ANCHIETA, 1988, p. 93).

Mediante o exposto acima, o que se percebe do texto é o modo como era ensinado aos aprendizes sob a ótica do professor, no caso, os padres, que apresentavam a literatura a partir de sua fé cristã. Nesse contexto, o eu-lírico apresenta a fragilidade do ser humano diante da Virgem Maria, porém, ela aparece, com piedoso amor, para salvar aquele que se arrepende de seus erros. Entretanto, o texto era ensinado apenas sob o ponto de vista do professor, não havia nenhuma discussão com o aluno sobre o seu conteúdo e a sua forma textual.

Dessa maneira, compreende-se que no período colonial, o Ensino de Literatura no Brasil era distanciado da realidade do aluno e isso acontecia, segundo Malard (1985) porque existia uma elitização que não condizia com a realidade do aluno. De tal modo, essa autora aponta que o ensino de literatura era transmitido nas escolas de maneira periódica, como se cada movimento ou Escola Literária não estivesse interligada uma com a outra, como, por exemplo, a religiosidade apresentada no Barroco, como mostra o trecho do poema Buscando a Cristo, de Gregório de Matos:

A vós correndo vou, braços sagrados,

Nessa cruz sacrossanta descobertos,

Que, para receber-me, estais abertos,

E, por não castigar-me, estais cravados.

(MATOS, 1984 apud PEIXOTO, 1929, p. 8).

A estrofe mostra que a fé cristã está presente na vida dos seres humanos em todos os tempos. A crença em Cristo crucificado, de braços abertos, representando a figura de um Deus acolhedor a todos aqueles que se arrependem de seus erros, não era utilizada somente no período barroco, mas prevalece até os dias atuais. Contudo, na maioria das vezes, a religiosidade barroca é estudada, na sala de aula, como se fosse uma crença apenas do século XVII, por se tratar de um ensino historicizado. No entanto, sabe-se que as crenças religiosas fazem parte da construção histórico-cultural das sociedades em todas as épocas.

Nesse mesmo sentido, faz-se necessário mostrar outro exemplo: o sentimentalismo romântico, uma vez que, esse movimento literário apresenta os sentimentos e as emoções humanas, que são fatores recorrentes nas narrativas. Os escritores trazem à tona o destino de personagens que estão envolvidas na trama de maneira sentimental e buscam a sua realização amorosa. Como no romance Senhora, em que José de Alencar apresenta a história da jovem Aurélia, que age movida pelo sentimento amoroso. Esse sentimentalismo é descrito da seguinte maneira, pela protagonista:

[...] quando ele convencer-me do seu amor e arrancar do meu coração a última raiz desta dúvida atroz que o dilacera; quando nele encontrar-te a ti, 
o meu ideal, o soberano de meu amor; quando tu e ele fores um, e eu não vos possa distinguir nem no meu afeto, nem nas minhas recordações, nesse dia eu the pertenço... (ALENCAR, 1974, p. 170-171).

O sentimento de amor e de desejo pela pessoa amada é visível na fala de Aurélia. Todavia, vale ressaltar que o sentimento representa as emoções dos seres humanos, que podem se manifestar através de amor, carinho, afeto, ódio, rancor, entre outros. Por serem sentimentos universais, é preciso que o professor-mediador trabalhe os textos literários de maneira contextualizada, para que ocorra mais interesse por parte do aluno em ler e compreender o que de fato é a literatura e a sua importância na vida dos seres humanos.

Nesse sentido, Leahy-Dios (2004) argumenta que a literatura precisa ser ensinada em conjunção com a vida dos seres humanos, para que estes possam refletir sobre os acontecimentos e compreender o seu significado. Se os textos literários forem ensinados mostrando apenas os períodos e autores canonizados das Escolas Literárias, compreendese que a estética e o conteúdo presentes no texto literário ficarão distantes do entendimento do público (aluno), pois estará distante de sua realidade.

Sobre esse prisma, Perrone-Moisés (2007) aponta a literatura como um instrumento de conhecimento do outro e de autoconhecimento, porque a ficção, ao mesmo tempo que representa a realidade, mostra que, através do imaginário, outras realidades são possíveis. Nesse caso, compreende-se que os textos literários devem ser analisados sob a ótica do professor e dos alunos. Nesse contributo, Freire (1997) defende que o melhor método de ensinar é àquele que propõe a aproximação com o objeto, porque cada texto tem o leitor como gerador de intenção. Candido (2006) argumenta que nos textos literários há aspectos sociais, culturais e históricos, e, por isso, não devem ser trabalhados sob uma ótica unilateral, sendo assim, para a sua compreensão faz-se necessário um posicionamento de diferentes concepções acerca dessa temática.

Seguindo essa trajetória, Zilberman e Silva (2008) argumentam que o ensino de literatura, no Brasil, não apresentou mudanças nas últimas décadas do século $X X$, em desinência ao projeto de educação, que foi pensado pelos governos e autoridades como "um processo de formação de mão de obra para abastecer novos postos de trabalho" (GALVÃO; SILVA, 2017, p. 2010) nas indústrias, resultantes do processo de modernização da sociedade. Esses autores esclarecem que o processo de ensino em prol da preparação para o trabalho contribui para a deficiência na leitura e na compreensão do texto literário pelo aluno, cuja finalidade de ensino é posta como instrumento para mão de obra no mercado. Britto (2012) assevera que a leitura instruída pelo professor promove ao alunoaprendiz o hábito e o entusiasmo de ler obras literárias. No entanto, o gosto por determinadas obras, autores e estilos acontecem de acordo com a variedade de leitura, que é posta ao contato do leitor e de seus conhecimentos, de seus interesses e modo de vida. Esse autor também esclarece que o gosto pela leitura, por parte do aluno, é aprendido de acordo com o estímulo e incentivo do professor.

Nessa consonância, Leahy-Dios (2004) mostra que o ensino de literatura está em 
crise, porque os conteúdos foram reduzidos às exigências dos exames vestibulares, ao priorizar os nomes de obras, autores e as suas características, sem uma visão crítica sobre o texto. Essa autora também argumenta sobre a necessidade de questionar os livros didáticos, que aparecem como instrumentos constituídos por regras preestabelecidas e distantes da realidade dos alunos. Além dos aspectos apresentados, Galvão e Silva (2017) apresentam ainda, a falta de valoração do professor, que recebe um salário não condizente com seu trabalho, e que, muitas vezes, precisa trabalhar com carga horária excessiva, ficando assim, com pouco ou nenhum tempo para pensar em diferentes estratégias de aula, que despertam o interesse do aluno.

Diante dessas constatações, torna-se relevante pensar no ensino de literatura e perda de espaço dessa disciplina no ensino formal, tendo sido assumida por profissionais de Letras de diferentes nacionalidades, feição de alerta como sugere a obra de Todorov: $A$ literatura em perigo (2010), a qual chama a atenção da sociedade para a necessária conexão entre vida e literatura visto que, muitas vezes, há um afastamento entre o texto literário e o contexto social do estudante. Nessa perspectiva, compreende-se nas implicações de um ensino que fragiliza a própria ideia em que o ensino de literatura, de fato, acontece porque, ao estudá-la, há clareza das ocorrências de todos os segmentos sociais de uma região.

Todavia, os Parâmetros Curriculares Nacionais do Ensino Médio (PCNEM), publicados em 2000 pelo Ministério da Educação e Cultura (MEC) defendem que o Ensino de Literatura como disciplina deve ser transmitido independente do Ensino de Língua Portuguesa, conforme estava previsto na Lei de Diretrizes e Bases da Educação (LDB) $n^{\circ}$ 5692/71, a qual esclarece que a separação entre as disciplinas de Língua Portuguesa, Literatura e Redação, ajuda na compreensão do aluno aos textos literários (BRASIL, 2000). Assim, entende-se que o documento visa alicerçar o ensino da gramática incorporado à produção textual e o ensino da literatura à prática de leitura.

Para a BNCC (Base Nacional Comum Curricular), publicada em 2017, com fundamento na LDB $n^{\circ}$ 9394/96, defende que a leitura e compreensão de textos literários devem permanecer ativas no Ensino Médio, por ser uma disciplina que possui grande importância, pois enriquece a percepção estética e a visão de mundo do aluno, além de propiciar a exploração de emoções. No entanto, com o processo de ensino acelerado e da divisão entre o estudo de outros gêneros artísticos como cinema e mídia, houve uma simplificação no ensino de literatura, o qual se resumiu aos estudos das biografias dos autores a características de época, o que coloca o texto literário em segundo plano, no Ensino Médio (BRASIL, 2017).

Dessa forma, o que se observa de ensino na disciplina de Literatura do Ensino Médio, no século XX, no Brasil, é uma preparação para os processos seletivos de vestibulares, centrando apenas na compreensão das escolas e movimentos literários, suas características e biografia dos autores e não como um estímulo a leituras e às discussões críticas a respeito do conteúdo dos textos e dos acontecimentos históricos. 
Nesse aspecto, Zilberman (2010) apresenta a crise, no Ensino de Literatura, em decorrência do processo de industrialização, que visa a preparação do sujeito para o trabalho, fazendo com que o conteúdo de literatura esteja focado nos conteúdos de exames de vestibulares. Um dos sintomas dessa crise foi a consequência da falta de leitura do aluno e de seu desconhecimento para com a estética do texto, a historicidade e o conteúdo, que se inicia com a leitura crítica e as discussões em sala de aula.

Mediante ao exposto, a autora Zilberman (2010) sugere uma ênfase maior no ensino de literatura com base nos fatos, na estética, no aspecto e no conteúdo dos textos literários, mostrando, de fato, o que é literatura, ao invés de utilizá-la apenas para o exame vestibular e com perspectivas que privilegiam somente o ponto de vista histórico e bibliográfico, isso porque o ensino dessa disciplina faz-se necessário ao aprendizado do conteúdo articulado à realidade do aluno.

Assim, torna-se possível observar que o ensino de literatura precisa ser discutido pelos profissionais dessa disciplina, uma vez que, se acentua a cada dia, segundo Santos e Jorge (2014) a carência de leitura e de perspectiva crítica sobre os textos literários. Percebe-se que a função de um professor de literatura é desafiada a cada momento, primeiro pela contradição, na evidência da importância da literatura para a vida humana e, ao mesmo tempo, pelo fato de ser ignorada pela sociedade, em segundo lugar, é um desafio imenso para o docente levar esse contexto literário ao aluno de modo que ele a conceba como uma tarefa agradável e significativa para a sua vida.

Todavia, ao lembrar que, no ensino de literatura, a contextualização tornou-se fundamental para a compreensão, aprendizagem e gosto pela leitura, por parte do aluno, é necessário que o professor ensine essa disciplina de forma articulada com a realidade. A título de exemplo, pode-se ilustrar com o fragmento do conto "O tempo é chegado", homólogo a obra, do autor Euclides Neto, publicada, em 2001, que descreve como as terras brasileiras do Sul da Bahia foram exploradas em tempos coloniais. Assim, comenta o narrador:

Antes, os índios, nas liberdades da criação. Chegaram os caçadores. Toparam ipeca, plantinha rasteira e milagrosa: a copaíba, árvore linheira, galhuda, passando as outras, gorda de óleo grosso, curando enfermidades. Muitos foram ficando por ali, abrindo a clareira, levantando casa de taipa, indaiá, chão socado. Sementes no útero da terra alvoroçada. Trilhas saindo daqueles brongos, procurando os paraceiros. Mandioca, cana, fumo, café. Cacau chegando. Floração. Safras ainda de quilos. Suor dos homens escorrendo nos eitos. Mulheres morriam no parto, homens esmagados sob as derrubadas dos machados, o pico-de-jaca matando meninos que metiam a mão nos ocos para tirar buguelos de periquito. Cruz nas encruzilhadas, testemunhando a despedida também dos que iniciaram a luta para tomar o trabalho do outro. A natureza sempre lutando contra o inimigo cruel, vingando-se com as forças telúricas, impiedosamente. (EUCLIDES NETO, 2001, p. 11).

O excerto inicia-se tratando dos tempos coloniais, mostrando que o Brasil era povoado por indígenas. Mas, com a colonização, a mata originária foi derrubada para a plantação do 
cacau, além do processo de construção de moradia. Portanto, o fragmento apresentou a escravização como: "suor dos homens escorrendo nos eitos", assim como alguns sendo mortos, ou "esmagados" de maneira violenta, como forma de opressão para que ocorresse, com mais rapidez, a derrubada das árvores, que se compreende como a invasão e o domínio dos colonos no país, no século XVI.

Ao observar o trabalho com o texto literário, em sala de aula, os professores precisam pensar primeiro na importância da obra e em uma maneira de mostrar para o aluno o contexto literário, para extrair do assunto do livro, uma discussão crítica, valorizando o ponto de vista do aluno. É preciso pensar na linguagem abordada e no texto, segundo Cosson (2006), por ser algo que precisa ser exercitado, traduzida em expressões que se faz tanto na escrita, quanto na forma e no conteúdo do texto. Pela linguagem do texto, compreende-se que o discurso transmite tanto o sentido das palavras e as criações do homem como a liberdade do imaginário e os acontecimentos físicos reais. A esse respeito, o autor aponta que:

É por possuir essa função maior de tornar o mundo compreensível transformando sua materialidade em palavras de cores, odores, saberes e formas intensamente humanas que a literatura tem e precisa manter um lugar espacial nas escolas. Todavia, para que a literatura cumpra seu papel humanizador, precisamos mudar os rumos de sua escolarização [...]. (COSSON, 2006, p. 17).

A literatura torna-se imprescindível na vida do ser humano, e, por isso, precisa manter o seu lugar no currículo escolar, pois assim, como, qualquer outra arte, torna o mundo mais compreensível. Nesse sentido, a desconexão do texto literário com o momento presente traz o sentido da literatura ausente no ensino, ao dificultar o gosto do aluno pela leitura e, ainda, a compreensão das obras literárias. A esse respeito, Candido (1995) sustenta a concepção que qualquer criação que desperta o imaginário, seja ela de caráter: ficcional, novelesco, dramático, prosaico ou poético e que se fizesse presente em todo o meio social, como parte de sua cultura, constituía-se em evidências, relativamente, comuns às pessoas, logo, isso concretizou-se em um contato direto com a literatura.

Dessa forma, Candido (2006) chama a atenção dos professores e da escola para os seguintes aspectos: os textos literários, por conter aspectos culturais, sociais e históricos, precisam ser contextualizados e compreendidos como um lugar verossímil, em que se encontra a referência de povos, de culturas, modos de vidas, regiões e principalmente, de verdades imaginadas, que trazem um elo entre o aluno-leitor e o texto. Portanto, é preciso ler e compreender a obra literária a partir de uma visão externa e investigativa, para que nela perceba os seus elementos estéticos.

Ao olhar por esse prisma, coloca-se em pauta, a questão da forma como o ensino de literatura está sendo trabalhado na sala de aula, de maneira descontextualizada com a realidade do aluno. Nesse sentido, é necessário que o professor trabalhe os textos literários de forma que sejam compreendidos pelo aluno-leitor, com o intuito de despertar, assim, o prazer pela leitura literária e sua compreensão sobre o meio social, psicológico e cultural. 


\section{Considerações finais}

No decorrer da leitura e análise de textos, compreende-se a importância da literatura como ensino e aprendizagem do aluno e a maneira como esse conhecimento é transmitido em sala de aula para as turmas de Ensino Médio. Desse modo, verifica-se que há uma valorização da literatura historicizada e periodizada, em relação ao próprio conhecimento do que, de fato, constitui-se a literatura.

Diante dessa análise, entende-se que a literatura constitui um manancial de riqueza, pois incorpora a arte como a linguagem, a estética e a representação de épocas de um povo, à medida que se valoriza a cultura, mas em contrapartida, nas salas de aula esse conhecimento está sendo simplificado, com foco somente nas obras cobradas pelos vestibulares, o que resulta em um conhecimento fragmentado do aluno sobre o que é a literatura.

Apesar de o PCNEM e a ABNCC questionarem sobre essa forma de ensino simplificado nas aulas de literatura, a grade curricular elege, frequentemente, como disciplina de maior importância, a gramática, porque deixa de apreciar e compreender o conteúdo e a estética dos textos literários.

Todavia, vale ressaltar que a literatura sempre esteve presente em todas as épocas, por todos os lugares, em diversos povos, sociedade, culturas e abrangendo variados conhecimentos da história da humanidade. Dessa forma, os textos literários possibilitam ao leitor o conhecimento de diversos espaços físicos, psicológicos e imaginários, ajudando-o na externalização de pensamentos e da imaginação que são imensuráveis. Nesse sentido, tais textos constituem uma forma de que o indivíduo aprecie a arte da linguagem, da escrita e desperte a sua imaginação.

Assim, percebe-se a necessidade de se estudar literatura, de maneira que ela seja compreendida e discutida como um instrumento de conhecimento dos povos, dos lugares, do outro e, também, do próprio leitor, pois os textos literários constituem-se em um saber, um rico conhecimento de história, tempo, espaço e épocas.

\section{Referências}

ALENCAR, José Martiniano de. Senhora, perfil de mulher. Rio de Janeiro: Editora Expressão e Cultura, 1974.

ALMEIDA, Maria do Socorro Pereira de Almeida. Literatura e ensino: perspectivas metodológicas. Rios Eletrônica, v. 8, n. 8, p. 7-19, dez. 2014.

ANCHIETA, José de. Poema da Bem-Aventurada Virgem Maria, Mãe de Deus. São Paulo: Loyola, 1988.

BRASIL. Ministério da Educação Média e Tecnológica. Parâmetros Curriculares Nacionais - Ensino Médio. Brasília: Ministério da Educação, 2000. 
BRASIL. Base Nacional Comum Curricular. Brasília: MEC, 2017. Disponível em: http://basenacionalcomum.mec.gov.br/images/BNCC_20dez_site.pdf. Acesso em: 22 dez. 2017.

BRITTO, Luiz Percival Leme. Inquietudes e desacordos: a leitura além do óbvio. Campinas/SP: Mercado das Letras, 2012.

CANDIDO, Antonio. Vários escritos. São Paulo: Duas Cidades, 1995.

CANDIDO, Antonio. Literatura e sociedade. Rio de Janeiro: Ouro sobre azul, 2006.

CARDOSO, Zélia de Almeida. O drama histórico latino e suas projeções no mundo renascentista e barroco. Letras Clássicas, n. 6, p. 161-195, 2002.

COSSON, Rildo. Letramento literário: teoria e prática. São Paulo: Contexto, 2006.

ECO, Humberto. Seis passeios pelo bosque da fiç̧ão. São Paulo: Editora Geral, 2000.

GALVÃO, André Luís Machado; SILVA, António Carvalho da. O ensino de literatura no Brasil: desafios a superar em busca de práticas mais eficientes. Letras \& Letras, Uberlândia, v. 33, n. 2, p. 209-228, jul./dez. 2017.

NETO, Euclides. O tempo é chegado. In: NETO, Euclides. O tempo é chegado. llhéus: Editus, 2001, p. 11-14.

FREIRE, Paulo. Pedagogia da autonomia: saberes necessários à prática educativa. São Paulo: Paz na terra, 1997.

LEAHY-DIOS, Cyana. Educação literária como metáfora social: desvios e rumos. São Paulo: Martins Fontes, 2004.

MALARD, Letícia. Ensino e Literatura no $2^{\circ}$ grau: problemas e perspectivas. Porto Alegre: Mercado Aberto, 1985.

PEIXOTO, Afrânio. Obras de Gregório de Matos - I - Sacra. Rio de Janeiro: Officina Industrial Graphica, 1929

PERRONE-MOISÉS, Leyla. Vira e mexe, nacionalismo: paradoxos do nacionalismo literário. São Paulo: Companhia das Letras, 2007.

SANTOS, Claudete Daflon dos; JORGE, Silvio Renato. Literatura e ensino: um tema e seus problemas. Gragoatá, Niterói, n. 37, p. 177-200, 2014.

SOUZA, Roberto Acízelo de. O império da eloquência: retórica e poética no Brasil oitocentista. Rio de Janeiro: EdUERJ: EDUFF, 1999.

TODOROV, Tzvetan. A literatura em perigo. Trad. de Caio Meira. 3. ed. Rio de Janeiro: DIFEL, 2010

ZILBERMAN, Regina; SILVA Ezequiel Theodoro. Literatura e pedagogia, ponto e contraponto. São Paulo: Global, 2008.

ZILBERMAN, Regina. A leitura e o ensino de literatura. Curitiba-PR: Ibpex, 2010. 


\section{NOTAS DE AUTORIA}

Juliana Cristina Ferreira (jujucris214@gmail.com) é Doutora em Estudos Literários pela Universidade Federal de Uberlândia - UFU, mestra em Estudos da Linguagem, pela Universidade Federal de Goiás/Regional Catalão, especialista em História do Brasil pela Universidade Federal de Goiás UFG/Regional Catalão, linguista pela Universidade Federal de Goiá - UFG/Regional Catalão. Pedagoga Pelo Centro de Ensino Superior de Catalão - CESUC.

\section{Como citar esse artigo de acordo com as normas da ABNT}

FERREIRA, Juliana Cristina. O ensino de literatura no Brasil: uma abordagem do currículo no Ensino Médio. Anuário de Literatura, Florianópolis, v. 26, p. 01-11, 2021.

\section{Contribuição de autoria}

Não se aplica.

\section{Financiamento}

Não se aplica.

\section{Consentimento de uso de imagem}

Não se aplica.

Aprovação de comitê de ética em pesquisa

Não se aplica.

\section{Conflito de interesses}

Não se aplica.

\section{Licença de uso}

Os/as autores/as cedem à Revista Anuário de Literatura os direitos exclusivos de primeira publicação, com o trabalho simultaneamente licenciado sob a Licenca Creative Commons Attribution (CC BY) 4.0 International. Estra licença permite que terceiros remixem, adaptem e criem a partir do trabalho publicado, atribuindo o devido crédito de autoria e publicação inicial neste periódico. Os autores têm autorização para assumir contratos adicionais separadamente, para distribuição não exclusiva da versão do trabalho publicada neste periódico (ex.: publicar em repositório institucional, em site pessoal, publicar uma tradução, ou como capítulo de livro), com reconhecimento de autoria e publicação inicial neste periódico.

\section{Publisher}

Universidade Federal de Santa Catarina. Programa de Pós-graduação em Literatura. Publicação no Portal de Periódicos UFSC. As ideias expressadas neste artigo são de responsabilidade de seus/suas autores/as, não representando, necessariamente, a opinião dos/as editores/as ou da universidade.

\section{Histórico}

Recebido em: $27 / 04 / 2020$

Aprovado em: $17 / 06 / 2020$

Publicado em: 23/04/2021 